\title{
A functional SNP in miR-625-5p binding site of AKT2 3 'UTR is associated with noise-induced hearing loss susceptibility in the Chinese population
}

\section{Boshen Wang \\ Southeast University \\ Juan Zhang \\ Southeast University \\ Lihong Yin \\ Southeast University \\ Yuepu Pu \\ Southeast University}

Long Miao ( $\nabla$ miaolong0308@163.com )

Southeast University https://orcid.org/0000-0001-6949-5855

\section{Research Article}

Keywords: Noise-induced hearing loss, AKT2, SNP, Susceptibility, has-miR-625-5p

Posted Date: February 23rd, 2021

DOl: https://doi.org/10.21203/rs.3.rs-234851/v1

License: (1) This work is licensed under a Creative Commons Attribution 4.0 International License. Read Full License

Version of Record: A version of this preprint was published at Environmental Science and Pollution Research on March 26th, 2021. See the published version at https://doi.org/10.1007/s11356-021-13649-4. 


\section{Abstract}

This study aimed to explore the association of several single nucleotide polymorphisms (SNPs) within the AKT2 gene and noise-induced hearing loss $(\mathrm{NIHL})$ susceptibility and explore the potential mechanism underlying NIHL. Three SNPs (rs2304186, rs41275750 and rs76524493) were genotyped in a Chinese population which consists of $690 \mathrm{NIHL}$ patients and 650 normal hearing controls. Bioinformatic analysis was conducted to predict the potential miRNA-binding site of SNPs. Cell transfection and dual-luciferase reporter assay were performed to investigate the potential molecular mechanism of SNPs involved in NIHL. The results revealed rs2304186 GT genotype $(\mathrm{OR}=1.41 ; 95 \% \mathrm{Cl}=1.09-1.83)$ and TT genotype $(\mathrm{OR}=1.51$; $95 \% \mathrm{Cl}=1.08-2.10)$ imparted increased risk of $\mathrm{NIHL}$, and the increased risk could also be found in a dominant model $(\mathrm{OR}=1.44 ; 95 \% \mathrm{Cl}=1.12-1.84)$. The stratification analysis showed that rs $2304186 \mathrm{GT} / \mathrm{TT}$ conferred a higher risk for NIHL, especially in subgroups of male, age (35-45 and > 45 years), noise exposure time (> 16 years), and noise exposure level ( $\leq 85$ and $\geq 92 \mathrm{~dB}$ ), compared with GG genotype. In addition, the haplotype TCCTACT (rs2304186-rs41275750-rs76524493) was associated with NIHL risk (OR $=1.19 ; 95 \% \mathrm{Cl}=1.02-1.40)$. Rs2304186 $\mathrm{G}$ allele combined with hsa-miR-625-5p mimics could significantly decrease the luciferase activity compared with T allele, indicating rs2304186 altered the binding affinity of hsa-miR-625-5p to SNP rs2304186 mutation region, thus directly targeting AKT2. In conclusion, our study provides evidence for the first time that SNP rs2304186 of AKT2 3'UTR affects NIHL susceptibility by affecting the binding affinity of has-miR-625-5p in an allele-specific manner and it may act as a potential biomarker of NIHL susceptibility.

\section{Introduction}

Occupational noise is known as a common harmful factor affecting workers' health in occupational health field. Noise-induced hearing loss ( $\mathrm{NIHL}$ ) has become the second leading form of progressive sensorineural hearing defect caused by occupational noise exposure, after age-related hearing impairment (Miao et al. 2019). In addition, NIHL is the most common occupation-related hearing defect and is an urgent public health issue around the world. The World Health Organization (WHO) previously reported that approximately $10 \%$ of population worldwide are exposed to high-intensity noise level environment and may develop NIHL (Basner et al. 2014). The previous study found that $16 \%$ of adult disabling hearing loss worldwide can be attributed to occupational noise, accounting for 4.1 million disability-adjusted life years (DALYs) (Nelson et al. 2005). Nowadays, in China, NIHL has become the third largest occupational health hazard, accounting for about one-sixth of the annual increase in occupational related-illnesses (Yu 2016).

$\mathrm{NIHL}$ is considered to be a complex hearing disorder caused by environmental factors and genetic effects. Previous studies have found individuals show different degrees of NIHL hazard even though they are in the similar noise environment, indicating that genetic susceptibility might involve in the process of NIHL (Sliwinska-Kowalska \&Pawelczyk 2013). Recently, numerous studies intending to identify NIHL-related pathogenic genes along with single nucleotide polymorphisms (SNPs) contributing to NIHL involves in several vital pathways including potassium recycling, oxidative stress, heat shock protein, apoptosis signaling and notch signaling pathways (Miao et al. 2019). However, the susceptibility genes responsible for $\mathrm{NIHL}$ have not been adequately explored. 
AKT, also called protein kinase B (PKB), is one of key molecules in the PI3K-AKT signaling pathway. There are three human isoforms of AKT, including AKT1, AKT2 and AKT3, encoding by AKT1/PKBa, AKT2/PKBb and AKT3/ PKBc, separately (Zhu et al. 2016). Human AKT2 gene is located in chromosome 19q13.1-q13.2 and is consist of 14 exons (Cheng et al. 1992). AKT2 is highly expressed in adipocytes and muscle tissue and is involved in insulin-mediated regulation of glucose homeostasis (Zdychova \&Komers 2005). AKT2 as key component of PI3K-AKT pathway, which participates in an extensive cellular biological processes, covering cell metabolism, survival, growth, and proliferation (Pereira et al. 2015). Dysregulation of AKT2 is concerned with several human diseases comprising cardiovascular, diabetes, cancer, and nerve system disorders (Hers et al. 2011). It has been indicated SNPs act an important type of genetic variations and affect individual's susceptibility to disease (Cargill et al. 1999). Previously, it was reported SNPs in AKT2 were related to gastric cancer (Zhang et al. 2014). Hildebrandt found AKT2 rs892119 was related to the survival of esophageal cancer (Hildebrandt et al. 2009). Moreover, a missense mutation R274H in AKT2 contributing to autosomal dominant inheritance of severe diabetes was observed in a previous study (George et al. 2004).

A previous correlation study found noise exposure could lead to energy and hypoxia metabolism disturbances of hair cells in inner ear, thus leading to hair cell death (Kurabi et al. 2017). However, associations between AKT2 SNPs and the risk of NIHL has not yet been investigated. Considering the important functional roles of AKT2 in cellular growth process, we speculated that potentially functional SNPs in AKT2 gene and their interactions might be responsible for NIHL susceptibility. Therefore, we executed a case-control study to confirm the possible relationships of the AKT2 SNPs (rs2304186, rs41275750 and rs76524493) and susceptibility to NIHL in a Chinese population and deduce the potential mechanism.

\section{Materials And Methods}

\section{Study subjects}

All recruited study subjects were the frontline workers chronically exposed to occupational noise in the workplaces between 2013 and 2018 in Jiangsu province, China. All workers were required to accept the annual occupational health check-up, including routine physical examination, peripheral venous blood collection and pure-tone audiometry (PTA). Additionally, professionals carried out a questionnaire survey to inquiry subjects' family history, personal medical history, smoking and drinking habits, and drug use. However, workers with familial hereditary deafness and blast deafness history, some diseases could impair normal hearing (e.g. nervous tinnitus, pyogenic tympanitis, skull trauma, etc.) or have recently taken harmful drugs (e.g. aminoglycosides, aspirin, quinolones, etc.) that can damage the inner ear were excluded.

The present study was approved by the Ethics Committee of Zhongda Hospital, Affiliated Hospital of Southeast University. Informed consents were also obtained from all participants.

\section{Pure-tone audiometric (PTA) examination}


After all subjects were asked to stop occupational noise exposure at least 12 hours or more, each subject received PTA examination performed by a certified audiologist in anacoustic room with Madsen Voyager 522 audiometer (Madsen, Taastrup, Denmark) at the frequencies of $0.5,1,2,3,4$, and $6 \mathrm{kHz}$, respectively. According to GB/T7582-2004, the raw data of hearing thresholds of both ears were revised by age and sex. The diagnosis criteria of NIHL and normal hearing are based on the Chinese Diagnostic Criteria of Occupational NIHL (GBZ 49-2014).

\section{Definitions of NIHL cases and normal hearing controls}

In the current study, we defined occupational noise exposure as equivalent continuous $\mathrm{dB}(\mathrm{A})$-weighted sound pressure levels of at least $85 \mathrm{~dB}(\mathrm{~A})$ during a nominal 8-hour working day. $\mathrm{NIHL}$ was defined as subjects with average binaural hearing threshold level at high frequencies $(3,4$ and $6 \mathrm{kHz})$ higher than 25 $\mathrm{dB}$. However, normal hearing was defined as subjects with average binaural hearing threshold level less than $25 \mathrm{~dB}$ at high frequencies. All subjects were divided into NIHL group and control group. The control subjects were frequency-matched with $\mathrm{NIHL}$ cases for sex and age. Eventually, the current study included $690 \mathrm{NIHL}$ patients and 650 controls.

\section{DNA extraction}

Peripheral venous blood used for DNA isolation was collected from each subject. Genomic DNA was collected with the RelaxGene Blood DNA Kit (Tiangen Biotech, Beijing, China) in accordance with the instructions and was stored at $-80^{\circ} \mathrm{C}$ until use.

\section{SNPs selection and genotyping}

Candidate SNPs in AKT2 gene were selected based on the HapMap database and previous results from the literature.(Genomes Project et al. 2015) In this study, the selection of candidate SNPs based on the following criteria: (1) identified by Haploview software; (2) minor allele frequency (MAF) $\geq 0.05$ for Chinese Han in Beijing (CHB) population; (3) $r^{2}$ for linkage disequilibrium (LD) value $>0.8$. In the end, three SNPs (rs2304186, rs41275750 and rs76524493) were selected for subsequent association studies.

Next generation sequencing was implemented for SNPs genotyping. Briefly, the economical and efficient method consisted of designing of chimeric specific primers containing the target and universal sequences used for three-round multiplex PCR, and the PCR products sequencing (Chen et al. 2016). In our study, the next generation sequencing was accomplished by Biowing Applied Biotechnology Company (Shanghai, China).

\section{Bioinformatics analysis}

For the interested and functional SNP rs2304186, which is in 3'UTR region of the AKT2 gene, therefore, we performed bioinformatic analysis to determine if it is located at the miRNA-binding site. Three tools, PicTar (Krek et al. 2005) TargetScan (Friedman et al. 2009) and MirSNP (Liu et al. 2012) were applied for this objective.

Previous studies have found the secondary structure of mRNAs could affect its approachability to miRNA (Mahen et al. 2010). In order to determine the possible effects of major allele $\mathrm{G}$ or minor allele $\mathrm{T}$ on the 
secondary structure of 3'UTR of AKT2 gene, the AKT2 3'UTR fragments along with different length containing allele $\mathrm{G}$ or allele T of rs2304186 were confirmed using RNAfold online tool of ViennaRNA web services (http://rna.tbi.univie.ac.at) together with the minimum free energy (MFE) algorithm (Gruber et al. 2008).

\section{Plasmid construction, cell culture and transfection}

To evaluate the role of AKT2 3'UTR segment containing either wild-type G allele or mutant T allele of SNP rs2304186, the plasmid containing the sequence of rs2304186 was synthesized by Hanbio, Biotechnology Co., Ltd (Shanghai, China) and was cloned into the psiCHECK-2 vector (Promega). The constructed vector was inoculated on the Luria-Bertani (LB) medium and then cultured on a shaking table at $37^{\circ} \mathrm{C}$ for $14 \mathrm{~h}$. The plasmids were isolated with high-purity plasmid extraction kit (QIAGEN) and subsequently sequenced.

Human embryonic kidney 293T cells (HEK293T) were purchased from Shanghai Institute of Biochemistry and Cell Biology, Chinese Academy of Sciences (Shanghai, China). The HEK293T cells were maintained in Dulbecco's modified Eagle medium (DMEM) (HyClone) with 10\% fetal bovine serum (FBS) (Sigma) in a humidified situation with $5 \% \mathrm{CO}_{2}$ at $37^{\circ} \mathrm{C}$. Besides, has-miR-625-5p and negative control of miRNA mimics were acquired from Hanbio (Shanghai, China).

$1.5 \times 10^{5}$ cells were cultured per well in 96 -well plates. When the cells reached $60 \%-70 \%$ confluence, $100 \mathrm{ng}$ of wild-type and mutant plasmids were co-transfected with 5 pmol has-miR-625-5p mimics or negative control of miRNA mimics into the cells using the Lipofectamine ${ }^{\text {TM }} 3000$ reagent (Invitrogen, Carlsbad, CA, USA).

\section{Dual-luciferase reporter assays}

After $48 \mathrm{~h}$ of transfection, cells were harvested and washed three times using the phosphate-buffered saline (PBS). The cells were adequately dissociated via adding $100 \mu$ of $1 \times$ passive lysis buffer (Promega, Madison, WI, USA). Dual luciferase activities were measured using the Dual-Luciferase Reporter Assay System (Promega, Madison, WI, USA). Relative luciferase activity was determined as the ratio of firefly luciferase activity to renilla luciferase activity. Three independent assays were implemented, and each assay was executed in triplicate.

\section{Statistical analysis}

The categorical and continuous variables were computed as the frequencies and mean \pm standard deviation (SD). Goodness-of-fit $\chi^{2}$ test was utilized to decide the Hardy-Weinberg equilibrium (HWE) of selected SNPs of the control subjects. Differences in age, noise exposure year, exposure level and binaural hearing threshold shifts were calculated by Student's $t$-test. Pearson's $\chi^{2}$ test were applied to determine the differences in allele and genotype frequencies of the SNPs between the NIHL cases and controls. Besides, logistic regression model was applied to adjust for the potential confounders (sex, age, smoking status and drinking status), and to determine the possible relationships between the allele and genotype, and NIHL risk, as well as the strength of association. The associations between the genotypes of each SNP and the high frequency hearing threshold shifts were calculated using one-way ANOVA. Moreover, haplotype analysis of the studied SNPs was carried out by using the SHEsis tool.(Shi \&He 2005) The interactions among the 
studied SNPs was analyzed applying multifactor dimensionality reduction (MDR) analysis. The statistical differences were regarded significant at a $p<0.05$. Statistical analyses were accomplished via employing SPSS software (SPSS, Chicago, Illinois, USA).

\section{Results}

\section{Characteristics of study subjects and HWE tests of selected SNPs}

Totally, 1340 subjects were recruited in our present study, consisting of $690 \mathrm{NIHL}$ cases and 650 controls. Demographic characteristics of the NIHL and control individuals are demonstrated in Table 1. There were no significant differences between the two groups in terms of age, sex, noise exposure time, smoking status, drinking status, and noise exposure level $(P>0.05)$. However, there was a significant difference in the high frequency hearing threshold between $\mathrm{NIHL}$ and control groups. The average high frequency hearing threshold for $\mathrm{NIHL}$ patients was significantly higher $(37.02 \pm 12.17)$ than that of controls $(16.88 \pm 4.92 ; P<$ 0.001).

General information for the three studied SNPs and the corresponding results of HWE tests are listed in Table S1. Three SNPs including rs2304186, rs41275750 and rs76524493 are located in 3'UTR region of AKT2. The genotype distributions of the three studied SNPs in the controls was in accord with HWE $(P>$ 0.05).

\section{Association between AKT2 SNPs and risk of NIHL}

As shown in Table 2, there were significant different in genotypes frequencies of AKT2 rs2304186 between the NIHL patients and controls. When the rs $2304186 \mathrm{GG}$ genotype was used as a reference, the GT and TT genotypes imparted increased risk of $\mathrm{NIHL}(\mathrm{OR}=1.41 ; 95 \% \mathrm{Cl}=1.09-1.83$ for GT genotype; $1.51 ; 1.08-2.10$ for TT genotype), and the increased risk could also be observed in a dominant model $(\mathrm{OR}=1.44 ; 95 \% \mathrm{Cl}=$ 1.12-1.84). Moreover, in the allelic model, rs $2304186 \mathrm{~T}$ allele conferred a significantly increased risk for NIHL $(\mathrm{OR}=1.23 ; 95 \% \mathrm{Cl}=1.05-1.44)$ compared with the $\mathrm{G}$ allele. Interestingly, rs 41275750 heterozygous $\mathrm{CG}$ genotype had marginal effect association with $\mathrm{NIHL}(\mathrm{OR}=0.70 ; 95 \% \mathrm{Cl}=0.49-1.01 ; P=0.052)$. However, the distribution of genotypes frequencies of rs 76524493 were not significant difference between two groups.

The stratification analysis showed rs 2304186 GT/TT conferred a higher risk for NIHL, especially in subgroups of male, age ( $35-45$ and $>45$ years), and work time with noise ( $>16$ years) $(\mathrm{OR}=1.52 ; 95 \% \mathrm{Cl}=$ 1.17-1.96 for male; $1.53 ; 1.06-2.20$ and $1.75 ; 1.07-2.88$ for age $35-45$ and $>45$ years; $1.55 ; 1.09-2.21$ for noise exposure time $>16$ years), compared with rs 2304186 GG genotype (Table 3 ). For individuals exposed to occupational noise level $\leq 85 \mathrm{~dB}$, those carrying the rs2304186 GT/TT had a higher risk for NIHL $(\mathrm{OR}=1.71$; $95 \% \mathrm{Cl}=1.16-2.54)$. Moreover, individuals exposed to $\geq 92 \mathrm{~dB}$ carrying rs2304186 GT/TT also showed an increased risk for $\mathrm{NIHL}(\mathrm{OR}=1.55 ; 95 \% \mathrm{Cl}=1.05-2.30)$. We further conducted a stratified analysis of rs41275750 and NIHL risk in dominant model, the corresponding results are demonstrated in Table S2. Our data showed that individuals aged $35-45$ years $(\mathrm{OR}=0.53 ; 95 \% \mathrm{Cl}=0.31-0.89)$ and exposed to noise 86-91 $\mathrm{dB}(\mathrm{OR}=0.36 ; 95 \% \mathrm{Cl}=0.15-0.85)$ carrying $\mathrm{CG} / \mathrm{GG}$ genotypes exhibited a significantly decreased risk for NIHL, suggesting rs 41275750 CG/GG genotypes were protective factors for NIHL. 
Table 4 summarizes the haplotype frequencies of selected three SNPs between NIHL group and control group. Three common haplotypes (frequency $>2 \%$ ) originated from the three SNPs were identified, and the rest of the haplotypes (frequency $<2 \%$ ) were coalesced into the mixed group. We found that the haplotype TCCTACT (rs2304186-rs41275750-rs76524493) was associated with an increased risk of NIHL (OR = 1.19; $95 \% \mathrm{Cl}=1.02-1.40)$.

\section{Association between thehigh frequency hearing threshold shiftand SNP genotypes}

The association analysis results between the high frequency hearing threshold shift and genotypes of rs2304186, rs41275750 and rs76524493 in all subjects were demonstrated in Fig. 1. For rs2304186, the range of high frequency hearing threshold shift was $25.61 \pm 13.18 \mathrm{~dB}$ at GG genotype, but the GT and TT genotypes were $28.28 \pm 13.26 \mathrm{~dB}$ and $30.11 \pm 13.87 \mathrm{~dB}$. Subjects carrying rs2304186 GT and TT genotypes were observed to possess higher high frequency hearing threshold shifts than the individuals carrying GG genotype $(P=0.007$ and $P<0.001$, respectively). However, no significant statistical differences in terms of the high frequency hearing threshold shift between the genotypes of rs41275750 and rs76524493 were found $(P>0.05)$.

\section{Multifactor dimensionality reduction (MDR) analysis of interactions between SNPs}

The corresponding results of MDR analysis on the interactions between the three SNPs are displayed in Table S3 and Fig. S1. Fig. S1 shows that the distributions of high-risk and low-risk genotypes in the best locus model. The interaction results indicated that the interactions among rs2304186, rs41275750 and rs76524493 were associated with an increased risk of NIHL $(P=0.0107)$.

\section{Prediction of RNA secondary structures of AKT2 3'UTR harboring rs2304186}

The secondary structures of AKT2 3'UTR segment containing G allele or T allele of rs2304186 were explored by RNAfold. In this study, four different lengths including 85, 105, 125, and 205 bp were used for prediction. Four predictions accordantly indicated rs2304186 G allele mutates to T allele could alter the MFE, suggesting SNP rs2304186 might be associated with the alteration of mRNA secondary structure of AKT2 3'UTR and might influence the accessibility of miRNA target site (Fig. 2A-D).

\section{Prediction of miRNAs that potentially bind to AKT2 rs2304186}

Three online tools were applied to determine if functional SNP rs2304186 is located at miRNA target site. We found has-miR-625-5p could target AKT2 rs2304186 (Fig. 2E). has-miR-625-5p was confirmed by the three tools that it could perfectly match with the $\mathrm{G}$ allele of rs2304186 in the miRNA seed region.

\section{Analysis of SNP rs2304186 interfered with the interaction between hsa-miR-625-5p and AKT2}

AKT2 SNP rs2304186 is located in the 3'UTR of AKT2, to assess whether or not the rs2304186 G > T variant would affect the binding of the predicted has-miR-625-5p to the 3'UTR of AKT2 mRNA, two recombinant constructs containing the $\mathrm{G}$ allele or T allele were transiently co-transfected with hsa-miR-625-5p or 
corresponding negative control mimics into HEK293T cells. As indicated in Fig. 3, a notable decrease of luciferase activity was found in the transfected group of AKT2 3'UTR wild G allele together with hsa-miR625-5p, whereas the luciferase activity containing 3'UTR of the mutant T allele was not visibly changed compared with the corresponding control. Moreover, we found the luciferase activity of the reporter containing $\mathrm{G}$ allele combined with hsa-miR-625-5p was decrease by about $50 \%$ compared with the $T$ allele in the presence of hsa-miR-625-5p $(P<0.001)$. Therefore, these results indicated that the $\mathrm{G}$ allele of SNP rs 2304186 had stronger binding with hsa-miR-625-5p, that is, hsa-miR-625-5p might play regulatory role in directly targeting AKT2 with the rs $2304186 \mathrm{G}$ allele. Meanwhile, it is indicated that the SNP rs2304186 may modify miRNA-AKT2 gene regulation by affecting the binding of has-miR-625-5p in an allele-specific manner, eventually causing NIHL susceptibility.

\section{Discussion}

$\mathrm{NIHL}$ is a complicated sensorineural hearing loss that caused by the combination of environmental factors and genetic effects (Miao et al. 2019). The incidence of NIHL is gradually increasing around the world and severely endangers human health. SNP is known as the most common forms of genetic variations in the humans and affect individual's susceptibility to disease (Cargill et al. 1999). Therefore, the identification of key SNPs associated with NIHL risk is so essential for understanding this disease. Nowadays, some NIHLrelated susceptibility genes and SNPs have been identified, involving in several pathways including oxidative stress, potassium recycling, heat shock protein, etc (Miao et al. 2019).

In our study, the genetic association study on three polymorphisms (rs2304186, rs41275750 and rs76524493) in AKT2 gene in $690 \mathrm{NIHL}$ patients and 650 controls was investigated. The results showed the rs2304186 GT/TT genotypes are associated with a significantly increased risk of NIHL. Besides, the haplotype TCCTACT (rs2304186-rs41275750-rs76524493) imparts an increased risk of NIHL. Our findings support the hypothesis that AKT2 polymorphism rs2304186 might involve in the susceptibility to NIHL in the Chinese population.

AKT2 as a key component of PI3K-AKT pathway, which implicates in a wide range of cellular processes, such as cell growth, proliferation and survival (Pereira et al. 2015). To date, several polymorphisms in AKT2 gene have been confirmed to be implicated in several human diseases, such as gastric cancer, esophageal cancer and diabetes (George et al. 2004, Hildebrandt et al. 2009, Zhang et al. 2014) indicating that some AKT2 polymorphisms might play a crucial role in human diseases. Noise exposure can cause energy and hypoxia metabolism disorders of hair cells in inner ear, leading to hair cell death (Kurabi et al. 2017). Previous studies found that during noise exposure, the level of 8-iso-prostaglandin $F(2 a l p h a)$ in the inner ear rises and causes cochlear vasoconstriction and blood circulation disorder (Miller et al. 2003). After noise exposure, the blood circulation of the cochlea gradually restores, leading to the cochlear ischemiareperfusion injury, thus causing mitochondrial dysfunction and the increased productions of ROS triggering oxidative stress and inflammatory response (Honkura et al. 2016). PI3K-AKT signaling pathway has been identified to play a major part in regulating inflammatory responses (Sun et al. 2019). Currently, related studies have found inflammatory response is the essential response and involves in the pathogenesis of cochlear damage induced by noise (Yang et al. 2016). In addition, studies on animals also revealed noise- 
induced differentially expressed genes of cochlear are associated with multiple inflammation-related pathways, covering the cytokine-cytokine receptor and chemokine signaling pathway, and p38/MAPK and JNK signaling pathways (Jamesdaniel et al. 2011, Murai et al. 2008, Patel et al. 2013). In our study, mutation from $\mathrm{G}$ allele to $\mathrm{T}$ allele at rs 2304186 of AKT2 gene was significantly associated with increased $\mathrm{NIHL}$ risk. In addition, our findings further suggested AKT2-mediated inflammation may be a potential molecular mechanism for NIHL.

In the stratification analysis, we found the rs 2304186 GT/TT conferred a higher risk for NIHL in noise exposure time $>16$ years group and noise exposure level $>92 \mathrm{~dB}$ group, suggesting long period and highlevel noise exposure combined with SNP rs2304186 of AKT2 could contribute to a higher NIHL risk. The findings of the interactions of gene-by-environment are consistent with the correlational studies on NIHL (Guo et al. 2017, Liu et al. 2010). Besides, we observed that the male carrying rs2304186 GT/TT genotypes had a significantly higher risk for NIHL compared with the subjects carrying GG genotype. The results are in accord with the preceding studies, showing the association between polymorphisms and NIHL is likely more common in males (Wang et al. 2017). Individuals aged $>35$ years with rs2304186 GT/TT exhibited a higher risk for $\mathrm{NIHL}$, suggesting age is always a risk factor affecting NIHL susceptibility. Haplotype analysis indicated the haplotype TCCTACT (rs2304186-rs41275750-rs76524493) was associated with an increased risk of NIHL. Most importantly, the individuals harboring rs2304186 GT/TT genotypes had a significantly higher level of high frequency hearing threshold shift than those with GG genotype. Taken together, our results have indicated the rs 2304186 GT/TT genotypes are associated with the NIHL susceptibility. Furthermore, we found that individuals aged 35-45 years and exposed to noise level 86-91 dB with rs 41275750 CG/GG genotypes exhibited a decreased risk for NIHL by stratification analysis, suggesting rs 41275750 CG/GG genotypes may be protective factors against for NIHL. Meanwhile, the results suggest that the general individuals without rs 41275750 mutant $\mathrm{G}$ allele as a protective factor, the NIHL prevention should pay more attentions to preventing age-related hearing loss and reducing noise exposure time and intensity, in order to accomplish individualized prevention.

It is widely considered that 3'UTR plays a critical role in potentially regulating the stability, translation and localization of mRNA. Previous studies observed when SNPs are located at the miRNA-binding site of 3'UTR and they can affect the biological function of miRNA by means of generating or removing binding site of miRNA in the target gene mRNA, thus causing the cellular dysfunction and resulting in the occurrence of diseases (Zhu et al. 2017). Recent studies have found functional SNP rs11077 in the 3'UTR of XPO5 involved in NIHL is disruptive to the miRNAs including miR-4763-5p, miR-5002-3p and miR-617 and affects $\mathrm{NIHL}$ susceptibility by disturbing XPO5 expression (Wang et al. 2020). Besides, studies have suggested that several SNPs in 3'UTR may affect the corresponding gene expression through influencing the binding affinity for specific miRNAs, causing the occurrence of diseases (Knox et al. 2018; Pirooz et al. 2018). Considering SNP rs2304186 is located at the 3'UTR of AKT2, we examined whether rs2304186 associated with NIHL influenced AKT2 expression. First, we used three tools (PicTar, TargetScan and MirSNP) to determine if SNP rs2304186 is located at miRNA target site. We found that has-miR-625-5p was confirmed by the three databases that it could perfectly match with the $G$ allele of SNP rs2304186 in the miRNA seed region. Next, we further performed vitro experiments to investigate its potential molecular mechanisms. The luciferase reporter assay results suggested the activity of the reporter containing 3'UTR of rs $2304186 \mathrm{G}$ allele of AKT2 
gene was decreased to $50 \%$ when co-transfected with has-miR-625-5p, whereas the reporter containing 3'UTR of T allele showed no significant alteration of luciferase activity compared with negative control. The findings showed the $G$ allele of rs 2304186 could enhance a binding site for has-miR-625-5p and affect miRNA-AKT2 gene regulation.

To our knowledge, has-miR-625-5p belongs to human miR-625 family. It has reported that miR-625 family members play a major part in the development and progression of several types of cancers (Lou et al. 2013; Wang et al. 2014). Zheng et al. (Zheng et al. 2015) confirmed that miR-625-3p exhibits oncogenic functions in colorectal carcinoma by regulating SCAI/E-cadherin/MMP9 pathway. Roth et al. (Roth et al. 2012) detected the expression of miR-625 in non-small cell lung cancer and found miR-625 may have a protective effect on the development of non-small cell lung cancer. In this study, we found has-miR-625-5p might be involved in NIHL through targeting AKT2 to regulate its expression, which could be modified by SNP rs2304186.

\section{Strengths And Limitations}

Nevertheless, there are some potential limitations to our study. First, all the subjects in the current study were only restricted to the Chinese population. The findings appeared to be more favorable to the Chinese population but not on behalf of other ethnic population. Second, out of the three selected SNPs in AKT2 gene, only rs 2304186 was significantly associated with NIHL. It may not be sufficiently to clarify such a complex disease with only single SNP. Third, the personal hearing protection measure of study participants was not taken into account, which might decrease the confidence level of the current results.

\section{Conclusions}

In conclusion, our current study provides evidence that SNP rs2304186 within miRNA-binding site of AKT2 3'UTR is associated with NIHL susceptibility in the Chinese population and might act by affecting the binding affinity of has-miR-625-5p. Therefore, functional SNP rs2304186 might be a potential biomarker of NIHL susceptibility for Chinese workers exposed to occupational noise. Moreover, our study indicates that the SNPs alter gene expression through miRNAs might be a crucial underlying molecular mechanism NIHL susceptibility.

\section{Declarations}

\section{Acknowledgments}

The authors thank every worker for their participations in this study.

\section{Authors' contributions}

YP designed the research study. LM and BW performed the research and analyzed the data. LM drafted the manuscript. JZ, LY critically reviewed and revised the manuscript. All authors read and approved the final manuscript. 


\section{Funding}

This study was supported by the Open Research Fund of State Key Laboratory of Bioelectronics, Southeast University.

\section{Data availability}

The datasets used and analyzed during the current study are available from the corresponding author on reasonable request.

\section{Compliance with ethical standards}

\section{Conflict of interest}

The authors declare that they have no conflicts of interest.

\section{Ethical approval}

The present study was approved by the Ethics Committee of Zhongda Hospital, Affiliated Hospital of Southeast University.

\section{Consent to participate}

Informed consent was obtained from all individual participants included in the study.

\section{Consent to publish}

The participant has consented to the submission of the case report to the journal.

\section{References}

Basner M, Babisch W, Davis A, Brink M, Clark C, Janssen S, Stansfeld S (2014) Auditory and non-auditory effects of noise on health. Lancet 383:1325-1332

Cargill M, Altshuler D, Ireland J, Sklar P, Ardlie K, Patil N, Shaw N, Lane CR, Lim EP, Kalyanaraman N, Nemesh J, Ziaugra L, Friedland L, Rolfe A, Warrington J, Lipshutz R, Daley GQ, Lander ES (1999) Characterization of single-nucleotide polymorphisms in coding regions of human genes. Nat Genet 22:231-238

Chen K, Zhou YX, Li K, Qi LX, Zhang QF, Wang MC, Xiao JH (2016) A novel three-round multiplex PCR for SNP genotyping with next generation sequencing. Anal Bioanal Chem 408:4371-4377

Cheng JQ, Godwin AK, Bellacosa A, Taguchi T, Franke TF, Hamilton TC, Tsichlis PN, Testa JR (1992) AKT2, a putative oncogene encoding a member of a subfamily of protein-serine/threonine kinases, is amplified in human ovarian carcinomas. Proc Natl Acad Sci U S A 89:9267-9271

Friedman RC, Farh KK, Burge CB, Bartel DP (2009) Most mammalian mRNAs are conserved targets of microRNAs. Genome Res 19:92-105 
Genomes Project C, Auton A, Brooks LD, Durbin RM, Garrison EP, Kang HM, Korbel JO, Marchini JL, McCarthy S, McVean GA, Abecasis GR (2015) A global reference for human genetic variation. Nature 526:68-74

George S, Rochford JJ, Wolfrum C, Gray SL, Schinner S, Wilson JC, Soos MA, Murgatroyd PR, Williams RM, Acerini CL, Dunger DB, Barford D, Umpleby AM, Wareham NJ, Davies HA, Schafer AJ, Stoffel M, O'Rahilly S, Barroso I (2004) A family with severe insulin resistance and diabetes due to a mutation in AKT2. Science 304:1325-1328

Gruber AR, Lorenz R, Bernhart SH, Neubock R, Hofacker IL (2008) The Vienna RNA websuite. Nucleic Acids Res 36:W70-W74

Guo H, Ding E, Bai Y, Zhang H, Shen H, Wang J, Song X, Cai W, Guo J, Zhu B (2017) Association of genetic variations in FOXO3 gene with susceptibility to noise induced hearing loss in a Chinese population. PLoS One 12:e0189186

Hers I, Vincent EE, Tavare JM (2011) Akt signalling in health and disease. Cell Signal 23:1515-1527

Hildebrandt MA, Yang H, Hung MC, Izzo JG, Huang M, Lin J, Ajani JA, Wu X (2009) Genetic variations in the $\mathrm{PI3K} / \mathrm{PTEN} / \mathrm{AKT} / \mathrm{mTOR}$ pathway are associated with clinical outcomes in esophageal cancer patients treated with chemoradiotherapy. J Clin Oncol 27:857-871

Honkura Y, Matsuo H, Murakami S, Sakiyama M, Mizutari K, Shiotani A, Yamamoto M, Morita I, Shinomiya N, Kawase T, Katori Y, Motohashi H (2016) NRF2 Is a Key Target for Prevention of Noise-Induced Hearing Loss by Reducing Oxidative Damage of Cochlea. Sci Rep 6:19329

Jamesdaniel S, Hu B, Kermany MH, Jiang H, Ding D, Coling D, Salvi R (2011) Noise induced changes in the expression of p38/MAPK signaling proteins in the sensory epithelium of the inner ear. J Proteomics 75:410424

Knox B, Wang Y, Rogers LJ, Xuan J, Yu D, Guan H, Chen J, Shi T, Ning B, Kadlubar SA (2018) A functional SNP in the 3'-UTR of TAP2 gene interacts with microRNA hsa-miR-1270 to suppress the gene expression. Environ Mol Mutagen 59:134-143

Krek A, Grun D, Poy MN, Wolf R, Rosenberg L, Epstein EJ, MacMenamin P, da Piedade I, Gunsalus KC, Stoffel M, Rajewsky N (2005) Combinatorial microRNA target predictions. Nat Genet 37:495-500

Kurabi A, Keithley EM, Housley GD, Ryan AF, Wong AC (2017) Cellular mechanisms of noise-induced hearing loss. Hear Res 349:129-137

Liu C, Zhang F, Li T, Lu M, Wang L, Yue W, Zhang D (2012) MirSNP, a database of polymorphisms altering miRNA target sites, identifies miRNA-related SNPs in GWAS SNPs and eQTLs. BMC Genomics 13:661

Liu YM, Li XD, Guo X, Liu B, Lin AH, Ding YL, Rao SQ (2010) SOD2 V16A SNP in the mitochondrial targeting sequence is associated with noise induced hearing loss in Chinese workers. Dis Markers 28:137-147 
Lou X, Qi X, Zhang Y, Long H, Yang J (2013) Decreased expression of microRNA-625 is associated with tumor metastasis and poor prognosis in patients with colorectal cancer. J Surg Oncol 108:230-235

Mahen EM, Watson PY, Cottrell JW, Fedor MJ (2010) mRNA secondary structures fold sequentially but exchange rapidly in vivo. PLoS Biol 8:e1000307

Miao L, Ji J, Wan L, Zhang J, Yin L, Pu Y (2019) An overview of research trends and genetic polymorphisms for noise-induced hearing loss from 2009 to 2018. Environ Sci Pollut Res Int 26:34754-34774

Miller JM, Brown JN, Schacht J (2003) 8-iso-prostaglandin F(2alpha), a product of noise exposure, reduces inner ear blood flow. Audiol Neurootol 8:207-221

Murai N, Kirkegaard M, Jarlebark L, Risling M, Suneson A, Ulfendahl M (2008) Activation of JNK in the inner ear following impulse noise exposure. J Neurotrauma 25:72-77

Nelson DI, Nelson RY, Concha-Barrientos M, Fingerhut M (2005) The global burden of occupational noiseinduced hearing loss. Am J Ind Med 48:446-458

Patel M, Hu Z, Bard J, Jamison J, Cai Q, Hu BH (2013) Transcriptome characterization by RNA-Seq reveals the involvement of the complement components in noise-traumatized rat cochleae. Neuroscience 248:1-16

Pereira L, Horta S, Mateus R, Videira MA (2015) Implications of Akt2/Twist crosstalk on breast cancer metastatic outcome. Drug Discov Today 20:1152-1158

Pirooz HJ, Jafari N, Rastegari M, Fathi-Roudsari M, Tasharrofi N, Shokri G, Tamadon M, Sazegar H, Kouhkan F (2018) Functional SNP in microRNA-491-5p binding site of MMP9 3'-UTR affects cancer susceptibility. J Cell Biochem 119:5126-5134

Roth C, Stuckrath I, Pantel K, Izbicki JR, Tachezy M, Schwarzenbach H (2012) Low levels of cell-free circulating miR-361-3p and miR-625* as blood-based markers for discriminating malignant from benign lung tumors. PLoS One 7:e38248

Shi YY, He L (2005) SHEsis, a powerful software platform for analyses of linkage disequilibrium, haplotype construction, and genetic association at polymorphism loci. Cell Res 15:97-98

Sliwinska-Kowalska M, Pawelczyk M (2013) Contribution of genetic factors to noise-induced hearing loss: a human studies review. Mutat Res 752:61-65

Sun X, Chen L, He Z (2019) PI3K/Akt-Nrf2 and Anti-Inflammation Effect of Macrolides in Chronic Obstructive Pulmonary Disease. Curr Drug Metab 20:301-304

Wang B, Ding E, Shen H, Wang J, Sun K, Chen S, Han L, Zhang H, Zhu B, Xu M (2017) Association of TagSNP in IncRNA HOTAIR with susceptibility to noise-induced hearing loss in a Chinese population. Hear Res 347:41-46 
Wang N, Wang B, Guo J, Zhang S, Han L, Zhang J, Zhu B (2020) Single-Nucleotide Polymorphisms in XP05 are Associated with Noise-Induced Hearing Loss in a Chinese Population. Biochem Res Int 2020:9589310

Wang Z, Qiao Q, Chen M, Li X, Wang Z, Liu C, Xie Z (2014) miR-625 down-regulation promotes proliferation and invasion in esophageal cancer by targeting Sox2. FEBS Lett 588:915-921

Yang S, Cai Q, Vethanayagam RR, Wang J, Yang W, Hu BH (2016) Immune defense is the primary function associated with the differentially expressed genes in the cochlea following acoustic trauma. Hear Res 333:283-294

Yu SF (2016) [Strengthen the research for the prevention and control of occupational noise-induced hearing loss in our country]. Zhonghua Lao Dong Wei Sheng Zhi Ye Bing Za Zhi 34:881-883

Zdychova J, Komers R (2005) Emerging role of Akt kinase/protein kinase B signaling in pathophysiology of diabetes and its complications. Physiol Res 54:1-16

Zhang QY, Cheng WX, Li WM, Au W, Lu YY (2014) Occurrence of low frequency PIK3CA and AKT2 mutations in gastric cancer. Mutat Res 769:108-112

Zheng H, Ma R, Wang Q, Zhang P, Li D, Wang Q, Wang J, Li H, Liu H, Wang Z (2015) MiR-625-3p promotes cell migration and invasion via inhibition of SCAl in colorectal carcinoma cells. Oncotarget 6:27805-27815

Zhu DL, Guo Y, Zhang Y, Dong SS, Xu W, Hao RH, Chen XF, Yan H, Yang SY, Yang TL (2017) A functional SNP regulated by miR-196a-3p in the 3'UTR of FGF2 is associated with bone mineral density in the Chinese population. Hum Mutat 38:725-735

Zhu J, Wang M, He J, Zhu M, Wang JC, Jin L, Wang XF, Yang YJ, Xiang JQ, Wei Q (2016) Polymorphisms in the AKT1 and AKT2 genes and oesophageal squamous cell carcinoma risk in an Eastern Chinese population. J Cell Mol Med 20:666-677

\section{Tables}




\begin{tabular}{|c|c|c|c|c|c|}
\hline \multirow[t]{2}{*}{ Variables } & \multicolumn{2}{|c|}{ Cases $(n=690)$} & \multicolumn{2}{|c|}{ Controls $(n=650)$} & \multirow[t]{2}{*}{$P$} \\
\hline & $\mathrm{n}$ & $\%$ & $\mathrm{n}$ & $\%$ & \\
\hline \multicolumn{5}{|l|}{ Age (years) } & $0.738^{a}$ \\
\hline Mean \pm SD & \multicolumn{2}{|l|}{$39.98 \pm 8.01$} & \multicolumn{2}{|l|}{$39.92 \pm 8.09$} & $0.889^{b}$ \\
\hline$<35$ & 182 & 26.4 & 178 & 27.4 & \\
\hline $35-45$ & 331 & 48.0 & 298 & 45.9 & \\
\hline$>45$ & 177 & 25.7 & 174 & 26.8 & \\
\hline \multicolumn{5}{|l|}{ Sex } & $0.941^{\mathrm{a}}$ \\
\hline Male & 649 & 94.1 & 612 & 94.2 & \\
\hline Female & 41 & 5.9 & 38 & 5.9 & \\
\hline \multicolumn{5}{|c|}{ Work time with noise (years) } & $0.192^{\mathrm{a}}$ \\
\hline Mean \pm SD & $18.08 \pm 9.07$ & & $17.41 \pm 8.88$ & & $0.171^{\mathrm{b}}$ \\
\hline$\leq 16$ & 331 & 48.0 & 335 & 51.5 & \\
\hline$>16$ & 359 & 52.0 & 315 & 48.5 & \\
\hline \multicolumn{5}{|c|}{ Smoking status } & $0.147^{a}$ \\
\hline No & 385 & 55.8 & 337 & 51.8 & \\
\hline Yes & 305 & 44.2 & 313 & 48.2 & \\
\hline \multicolumn{5}{|c|}{ Drinking status } & $0.812^{\mathrm{a}}$ \\
\hline No & 225 & 32.6 & 208 & 32.0 & \\
\hline Yes & 465 & 67.4 & 442 & 68.0 & \\
\hline \multicolumn{5}{|c|}{ High frequency hearing threshold $(\mathrm{dB})$} & $<0.001^{\mathrm{a}}$ \\
\hline Mean \pm SD & $37.02 \pm 12.17$ & & $16.88 \pm 4.92$ & & $<0.001^{b}$ \\
\hline$\leq 26$ & 78 & 11.3 & 650 & 100.0 & \\
\hline$>26$ & 612 & 88.7 & 0 & 0.0 & \\
\hline \multicolumn{5}{|c|}{ Expose level with noise (dB) } & $0.586^{a}$ \\
\hline Mean \pm SD & $87.54 \pm 7.61$ & & $87.27 \pm 7.97$ & & $0.524^{\mathrm{b}}$ \\
\hline$\leq 85$ & 286 & 41.5 & 269 & 41.4 & \\
\hline
\end{tabular}




$\begin{array}{lllll}86-91 & 126 & 18.3 & 106 & 16.3 \\ \geq 92 & 278 & 40.3 & 275 & 42.3\end{array}$

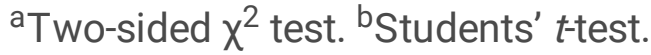

Abbreviations: SD, standard deviation; dB, decibel. 
Table 2 Genotype and allele frequency distributions of studied SNPs in NIHL cases and controls and the association with NIHL

\begin{tabular}{|c|c|c|c|c|c|c|c|c|}
\hline \multirow[t]{2}{*}{ SNP no. } & \multirow{2}{*}{$\begin{array}{l}\text { Genetic } \\
\text { models }\end{array}$} & \multirow[t]{2}{*}{ Genotypes } & \multicolumn{2}{|c|}{ Cases } & \multicolumn{2}{|c|}{ Controls } & \multirow[t]{2}{*}{$P^{a}$} & \multirow{2}{*}{$\begin{array}{l}\text { Adjusted } \\
\text { OR (95\% } \\
\mathrm{Cl})^{b}\end{array}$} \\
\hline & & & $\begin{array}{l}n= \\
690\end{array}$ & $\%$ & $\begin{array}{l}n= \\
650\end{array}$ & $\%$ & & \\
\hline & & & $\begin{array}{l}n= \\
638\end{array}$ & & $\begin{array}{l}n= \\
615\end{array}$ & & & \\
\hline \multirow[t]{10}{*}{ rs2304186 } & $\begin{array}{l}\text { Co- } \\
\text { dominant }\end{array}$ & GG & 155 & 24.3 & 195 & 31.7 & & $\begin{array}{l}1.00 \\
\text { (ref) }\end{array}$ \\
\hline & & $\mathrm{GT}$ & 351 & 55.0 & 311 & 50.6 & 0.008 & $\begin{array}{l}1.41 \\
(1.09- \\
1.83)\end{array}$ \\
\hline & & TT & 132 & 20.7 & 109 & 17.7 & 0.012 & $\begin{array}{l}1.51 \\
(1.08- \\
2.10)\end{array}$ \\
\hline & Dominant & GG & 155 & 24.3 & 195 & 31.7 & & $\begin{array}{l}1.00 \\
\text { (ref) }\end{array}$ \\
\hline & & $\mathrm{GT} / \mathrm{TT}$ & 483 & 75.7 & 420 & 68.3 & 0.003 & $\begin{array}{l}1.44 \\
(1.12- \\
1.84)\end{array}$ \\
\hline & Recessive & GG/GT & 506 & 79.3 & 506 & 82.3 & & $\begin{array}{l}1.00 \\
\text { (ref) }\end{array}$ \\
\hline & & TT & 132 & 20.7 & 109 & 17.7 & 0.183 & $\begin{array}{l}1.20 \\
(0.91- \\
1.60)\end{array}$ \\
\hline & Alleles & $\mathrm{G}$ & 661 & 51.8 & 701 & 57.0 & & $\begin{array}{l}1.00 \\
\text { (ref) }\end{array}$ \\
\hline & & $\mathrm{T}$ & 615 & 48.2 & 529 & 43.0 & 0.009 & $\begin{array}{l}1.23 \\
(1.05- \\
1.44)\end{array}$ \\
\hline & & & $\begin{array}{l}n= \\
681\end{array}$ & & $\begin{array}{l}n= \\
644\end{array}$ & & & \\
\hline \multirow[t]{5}{*}{ rs41275750 } & $\begin{array}{l}\text { Co- } \\
\text { dominant }\end{array}$ & $\mathrm{CC}$ & 619 & 90.9 & 568 & 88.2 & & $\begin{array}{l}1.00 \\
\text { (ref) }\end{array}$ \\
\hline & & CG & 58 & 8.5 & 76 & 11.8 & 0.052 & $\begin{array}{l}0.70 \\
(0.49- \\
1.01)\end{array}$ \\
\hline & & $\mathrm{GG}$ & 4 & 0.6 & 0 & 0.0 & 0.158 & - \\
\hline & Dominant & $\mathrm{CC}$ & 619 & 90.9 & 568 & 88.2 & & $\begin{array}{l}1.00 \\
\text { (ref) }\end{array}$ \\
\hline & & CG/GG & 62 & 9.1 & 76 & 11.8 & 0.108 & $\begin{array}{l}0.75 \\
(0.53-\end{array}$ \\
\hline
\end{tabular}




\begin{tabular}{|c|c|c|c|c|c|c|c|c|}
\hline & Recessive & $\mathrm{CC} / \mathrm{CG}$ & 677 & 99.4 & 644 & 100.0 & & $\begin{array}{l}1.00 \\
\text { (ref) }\end{array}$ \\
\hline & & GG & 4 & 0.6 & 0 & 0.0 & 0.148 & - \\
\hline & Alleles & C & 1296 & 95.2 & 1212 & 94.1 & & $\begin{array}{l}1.00 \\
\text { (ref) }\end{array}$ \\
\hline & & G & 66 & 4.8 & 76 & 5.9 & 0.228 & $\begin{array}{l}0.81 \\
(0.58- \\
1.14)\end{array}$ \\
\hline & & & $\begin{array}{l}n= \\
665\end{array}$ & & $\begin{array}{l}n= \\
626\end{array}$ & & & \\
\hline \multirow[t]{9}{*}{ rs76524493 } & $\begin{array}{l}\text { Co- } \\
\text { dominant }\end{array}$ & СТАСТ/СТАСТ & 598 & 89.9 & 549 & 87.7 & & $\begin{array}{l}1.00 \\
\text { (ref) }\end{array}$ \\
\hline & & СТАСТ/СТ & 63 & 9.5 & 76 & 12.1 & 0.129 & $\begin{array}{l}0.76 \\
(0.54- \\
1.09)\end{array}$ \\
\hline & & СТ/CT & 4 & 0.6 & 1 & 0.2 & 0.426 & $\begin{array}{l}3.52 \\
(0.39- \\
31.69)\end{array}$ \\
\hline & Dominant & СТАСТ/СТАСТ & 598 & 89.9 & 549 & 87.7 & & $\begin{array}{l}1.00 \\
\text { (ref) }\end{array}$ \\
\hline & & $\begin{array}{l}\text { CTACT/CT + } \\
\text { CT/CT }\end{array}$ & 67 & 10.1 & 77 & 12.3 & 0.204 & $\begin{array}{l}0.80 \\
(0.57- \\
1.13)\end{array}$ \\
\hline & Recessive & $\begin{array}{l}\text { CTACT/CTACT } \\
+ \text { CTACT/CT }\end{array}$ & 661 & 99.4 & 625 & 99.8 & & $\begin{array}{l}1.00 \\
\text { (ref) }\end{array}$ \\
\hline & & СТ/CT & 4 & 0.6 & 1 & 0.2 & 0.407 & $\begin{array}{l}3.61 \\
(0.40- \\
32.52)\end{array}$ \\
\hline & Alleles & СТАСТ & 1259 & 94.7 & 1174 & 93.8 & & $\begin{array}{l}1.00 \\
\text { (ref) }\end{array}$ \\
\hline & & СT & 71 & 5.3 & 78 & 6.2 & 0.332 & $\begin{array}{l}0.85 \\
(0.61- \\
1.18)\end{array}$ \\
\hline
\end{tabular}

${ }^{a}$ Two-sided $\chi^{2}$ test. ${ }^{b}$ Adjusted for age, sex, smoking and drinking status in logistic regression model.

Abbreviations: $\mathrm{OR}$, odds ratio; $\mathrm{Cl}$, confidence interval. 
Table 3 Stratified analysis of the association between rs2304186 and NIHL in a dominant model

\begin{tabular}{|c|c|c|c|c|c|c|}
\hline \multirow[t]{2}{*}{ Variables } & \multicolumn{2}{|c|}{ GG (case/control) } & \multicolumn{2}{|c|}{ GT/TT (case/control) } & \multirow[t]{2}{*}{$P^{a}$} & \multirow{2}{*}{$\begin{array}{l}\text { Adjusted OR (95\% } \\
\mathrm{Cl})^{\mathrm{b}}\end{array}$} \\
\hline & $\mathrm{n}$ & $\%$ & $\mathrm{n}$ & $\%$ & & \\
\hline \multicolumn{7}{|l|}{ Sex } \\
\hline Male & $142 / 187$ & $12.0 / 15.9$ & $458 / 393$ & $38.8 / 33.3$ & 0.001 & $1.52(1.17-1.96)$ \\
\hline Female & $13 / 8$ & $17.8 / 11.0$ & $25 / 27$ & $34.2 / 37.0$ & 0.284 & $0.70(0.21-2.39)$ \\
\hline \multicolumn{7}{|l|}{ Age (years) } \\
\hline$<35$ & $49 / 48$ & $14.2 / 13.9$ & $129 / 119$ & $37.4 / 34.5$ & 0.802 & $1.04(0.65-1.68)$ \\
\hline $35-45$ & $71 / 90$ & $12.3 / 15.6$ & $228 / 188$ & $39.5 / 32.6$ & 0.021 & $1.53(1.06-2.20)$ \\
\hline$>45$ & $35 / 57$ & 10.6/17.2 & $126 / 113$ & $38.1 / 34.1$ & 0.017 & $1.75(1.07-2.88)$ \\
\hline \multicolumn{7}{|c|}{ Work time with noise (years) } \\
\hline$\leq 16$ & $77 / 99$ & $12.2 / 15.7$ & $235 / 220$ & $37.2 / 34.9$ & 0.075 & $1.38(0.97-1.96)$ \\
\hline$>16$ & $78 / 96$ & $12.5 / 15.4$ & $248 / 200$ & $39.9 / 32.2$ & 0.018 & $1.55(1.09-2.21)$ \\
\hline \multicolumn{7}{|c|}{ Expose level with noise $(\mathrm{dB})$} \\
\hline$\leq 85$ & $61 / 85$ & $11.8 / 16.5$ & $204 / 165$ & $39.6 / 32.0$ & 0.006 & $1.71(1.16-2.54)$ \\
\hline $86-91$ & $34 / 25$ & $15.0 / 11.1$ & $87 / 80$ & $38.5 / 35.4$ & 0.464 & $0.78(0.43-1.43)$ \\
\hline$\geq 92$ & $60 / 85$ & 11.7/16.6 & $192 / 175$ & $37.5 / 34.2$ & 0.026 & $1.55(1.05-2.30)$ \\
\hline \multicolumn{7}{|c|}{$\begin{array}{l}\text { aTwo-sided } \chi^{2} \text { test. }{ }^{b} \text { Adjusted for age, sex, smoking and drinking status in logistic } \\
\text { regression model. }\end{array}$} \\
\hline
\end{tabular}


Table 4 Frequencies of inferred haplotypes among the cases and controls and their association with risk of $\mathrm{NIHL}$

\begin{tabular}{|c|c|c|c|c|c|c|c|}
\hline \multirow[t]{2}{*}{ Haplotypes ${ }^{a}$} & \multicolumn{2}{|l|}{ Cases } & \multicolumn{2}{|c|}{ Controls } & \multirow[t]{2}{*}{$P^{b}$} & \multirow[t]{2}{*}{ OR $(95 \% \mathrm{Cl})$} & \multirow[t]{2}{*}{ Global $P^{c}$} \\
\hline & $\mathrm{n}$ & $\%$ & $\mathrm{n}$ & $\%$ & & & \\
\hline GCCTACT & 586.26 & 46.9 & 592.04 & 50.3 & 0.100 & $0.88(0.75-1.03)$ & 0.076 \\
\hline GGCT & 61.19 & 4.9 & 69.96 & 5.9 & 0.257 & $0.82(0.57-1.16)$ & \\
\hline TССТАСТ & 598.74 & 47.9 & 512.96 & 43.6 & 0.030 & $1.19(1.02-1.40)$ & \\
\hline Others $^{d}$ & 3.81 & 0.3 & 1.04 & 0.1 & & 1.00 (ref) & \\
\hline \multicolumn{8}{|c|}{$\begin{array}{l}{ }^{\mathrm{a}} \text { The alleles of haplotypes were arrayed as rs } 2304186-\mathrm{rs} 41275750 \text {-rs } 76524493 .{ }^{\mathrm{b}} \text { Two-sided } \chi^{2} \text { test. } \\
\text { cGenerated by permutation test with } 1000 \text { times of simulation. }{ }^{\mathrm{d}} \text { Haplotypes with a frequency } \leq 0.02 \\
\text { (GCCT/TGCT/GGCTACT/TCCT/TGCTACT) were pooled into the mixed group. }\end{array}$} \\
\hline \multicolumn{8}{|c|}{ Abbreviations: OR, odds ratio; $\mathrm{Cl}$, confidence interval. } \\
\hline
\end{tabular}

\section{Figures}

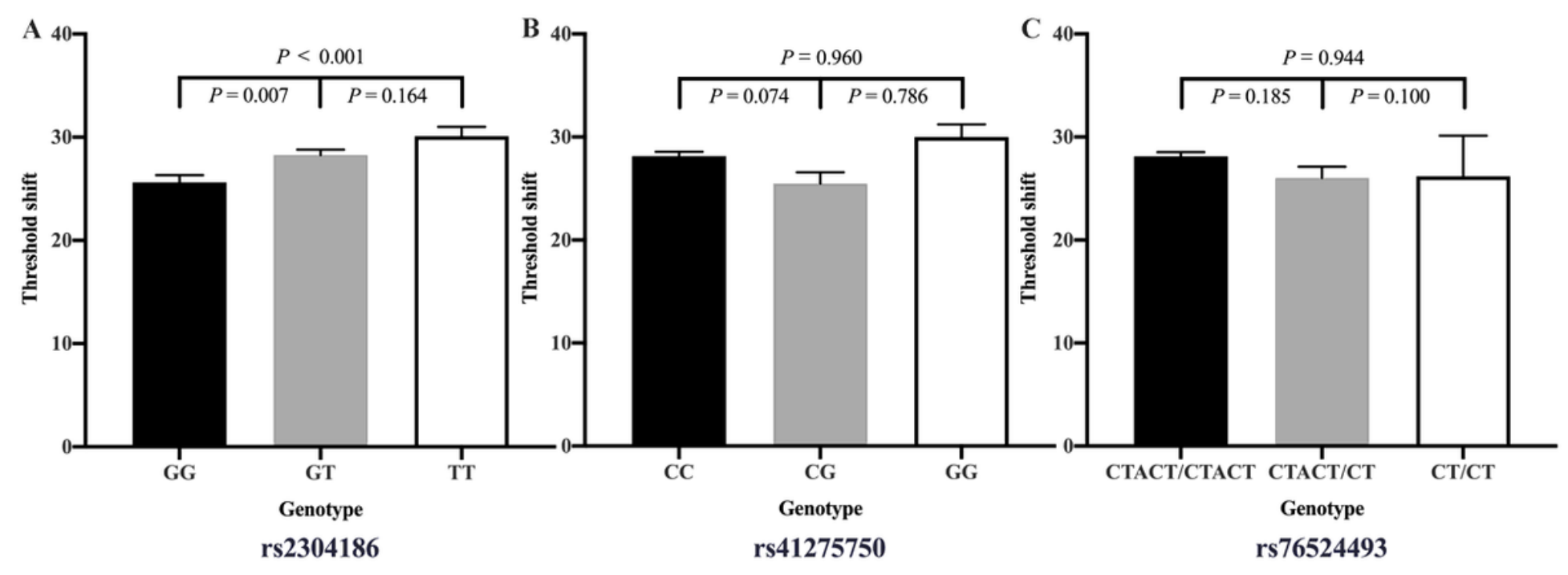

Figure 1

Comparison of high frequency hearing threshold shift of rs2304186 (A), rs41275750 (B), and rs76524493 (C) genotypes in all studied subjects. Data are presented as mean \pm SE analyzed by ANOVA. 
A

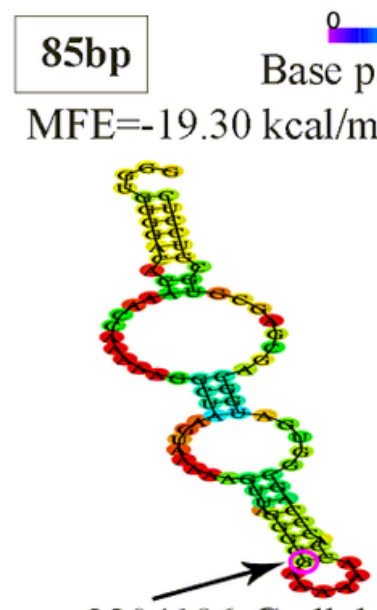

rs2304186-G allele

C

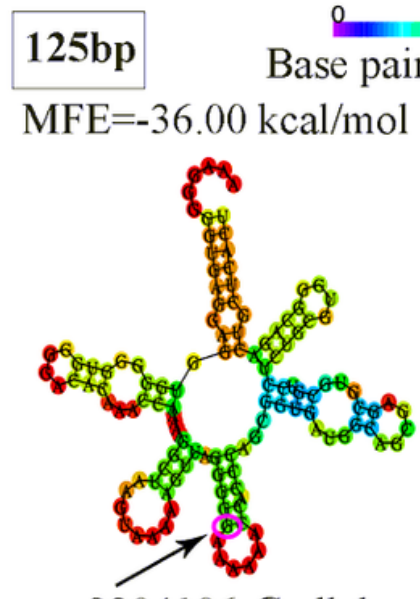

rs2304186-G allele

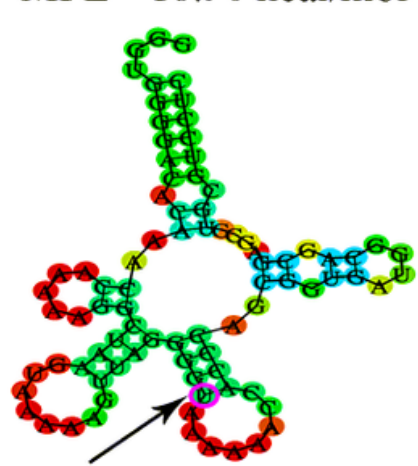

rs2304186-T allele

B

105bp Base pair probabilities

$\mathrm{MFE}=-26.50 \mathrm{kcal} / \mathrm{mol} \quad \mathrm{MFE}=-26.40 \mathrm{kcal} / \mathrm{mol}$

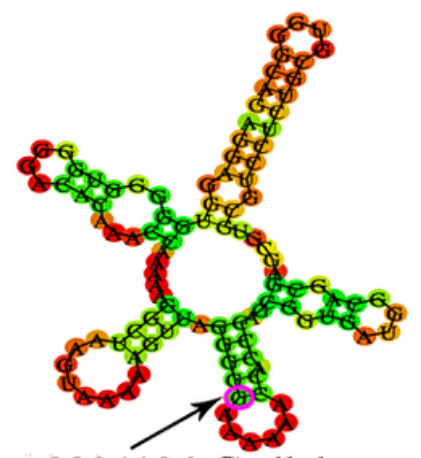

rs2304186-G allele

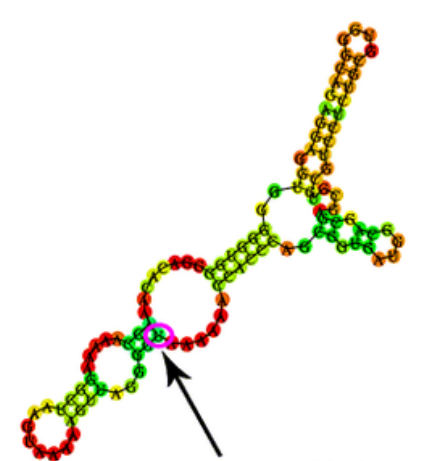

rs2304186-T allele

D

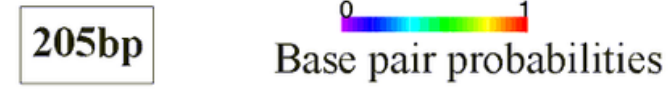

$\mathrm{MFE}=-61.30 \mathrm{kcal} / \mathrm{mol} \quad \mathrm{MFE}=-61.20 \mathrm{kcal} / \mathrm{mol}$

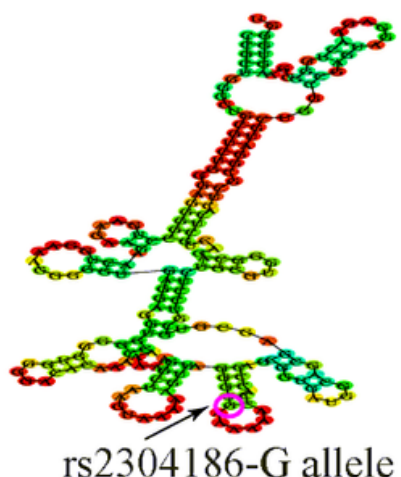

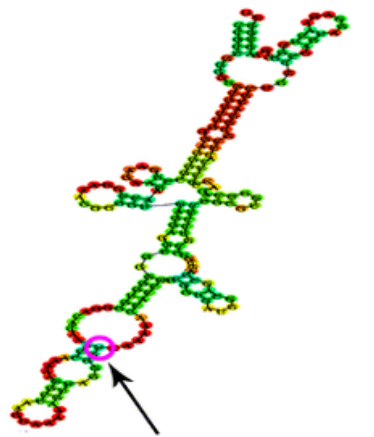

rs2304186-T allele $\mathbf{E}$

hsa-miR-625-5p $\quad 3^{\prime}$...CCUGAUAUCUUGAAAGGGGGA ...5'

AKT2 wildtype $\quad 5^{\prime} \ldots$ GCUGGGUGGUUUUUUCCCCCU... $3^{\prime}$

AKT2 mutant $\quad 5^{\prime} \ldots$ GCUGGGUGGUUUUUUACCCCU... $3^{\prime}$

\section{Figure 2}

The results of bioinformatics prediction about the secondary structure of AKT2 3'UTR containing either allele G or allele T of rs2304186 and the candidate miRNAs. (A-D) Predicted secondary structure of AKT2 3'UTR containing SNP rs2304186 using RNAfold online tool, mRNA sequences (85, 105, 125, and 205 bp, respectively) containing either allele G or allele T. SNP rs2304186 allele G mutates to allele T consistently changes the MFE. (E) Predicted candidate miRNA (hsa-miR-625-5p) could bind to the SNP rs2304186 of AKT2 3'UTR. SNP rs2304186 in the miRNA-binding site of AKT2 3'UTR is shown by red font. 


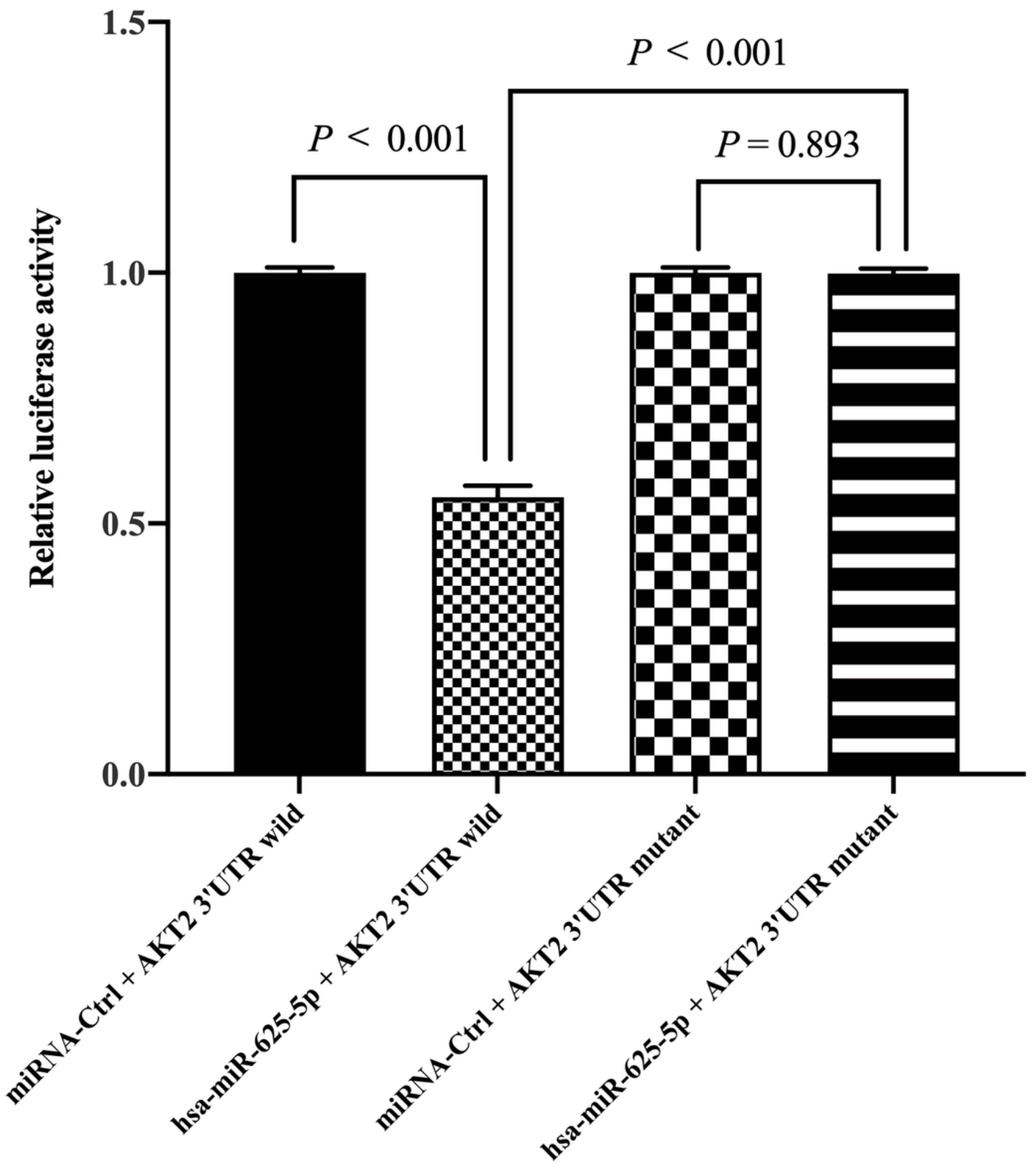

Figure 3

The luciferase activity in HEK293T cells transfected with a plasmid containing either the wild type (G allele) or the mutant allele (T allele) of SNP rs2304186 in AKT2 3'UTR together with has-miR-625-5p mimics or miRNA-negative control. Renilla luciferase was measured as an internal control, and firefly luciferase signals were normalized with renilla luciferase signals. Data were presented as the mean \pm SEM.

\section{Supplementary Files}


This is a list of supplementary files associated with this preprint. Click to download.

- SupplementaryMaterial.docx 